\title{
OBJETOS EDUCACIONAIS: A IMPORTÂNCIA DA ACESSIBILIDADE PARA INCLUSÃO ESCOLAR
}

Aline Aparecida Alcântara da Silva, Marcela Corrêa Tinti, Klaus Schlünzen Junior.

Universidade Estadual Paulista - UNESP, Presidente Prudente, SP. E-mail: alinealcantara@izaz.com.br.

\section{RESUMO}

No Centro de Promoção para Inclusão Digital, Escolar e Social (Cpides) são desenvolvidos projetos de extensão e pesquisa que promovam a inclusão social e escolar de pessoas com deficiência. As atividades apresentadas neste artigo foram desenvolvidas no Cpides com dois Estudantes Publico Alvo da Educação Especial (EPAEE), sendo um com Deficiência Intelectual e o outro com Síndrome de Down. O principal objetivo desta pesquisa foi analisar a importância da acessibilidade nos Objetos Educacionais (OE) para a inclusão. A metodologia conta com a utilização e análise do referido recurso e os resultados foram satisfatórios em relação à utilização dos $O E$ como ferramenta para inclusão, entretanto encontramos nos OE analisados ausência de recursos de acessibilidade. Constatamos que é de extrema importância à acessibilidade para a inclusão, pois, no caso dos $\mathrm{OE}$ os recursos de acessibilidade se tornam recursos importantes para o processo de inclusão.

Palavras-chave: Objetos Educacionais, Acessibilidade, Educação Inclusiva.

\section{OBJECTS EDUCATIONAL: ACCESSIBILITY OF IMPORTANCE TO SCHOOL INCLUSION}

\begin{abstract}
The Promotion Centre for Digital Inclusion, School and Social (Cpides), develops actions and research on social and educational inclusion of people with disabilities. The activities presented in this article were developed in Cpides two Public Students Target Special Education (EPAEE), one with Intellectual Disabilities and the other with Down syndrome. The main objective of this research was to analyze the importance of accessibility in Educational Objects (OE) for inclusion. The methodology relies on the use and analysis of that feature and the results were satisfactory regarding the use of EO as a tool for inclusion on the other hand have a barrier, lack of accessibility of most OE analyzed. We note that it is extremely important the accessibility for inclusion, as in the case of OE accessibility features indispensable for inclusion and use by EPAEE.
\end{abstract}

Keywords: Educational objects, Accessibility, Inclusive Education. 


\section{INTRODUÇÃO}

Atualmente, muito tem se discutido a respeito de acessibilidade para Estudantes Público Alvo da Educação Especial (EPAEE) em todas as etapas e modalidades da educação. Isso porque, acreditamos ser importante buscar estratégias que tornem as Tecnologias Digitais de Informação e Comunicação (TDIC) mais acessíveis com o intuito de favorecer a inclusão e o acesso de todas as pessoas, ao mundo digital independente de suas limitações físicas e cognitivas.

O trabalho apresentado foi realizado no Centro de Promoção para Inclusão Digital, Escolar e Social (Cpides), da Universidade Estadual Paulista "Júlio de Mesquita Filho" (UNESP), campus de Presidente Prudente, em que são realizados atendimentos pedagógicos, cujo intuito é favorecer inclusão educacional, social e digital de pessoas com deficiência, transtornos ou dificuldades de aprendizagem.

A Política Nacional de Educação Especial na Perspectiva da Educação Inclusiva (2007) define e implementa o AEE, como um serviço de educação especial que "[...] identifica, elabora e organiza recursos pedagógicos e de acessibilidades, que eliminem as barreiras para a plena participação dos estudantes, considerando suas necessidades específicas" (SEESP/ MEC, 2008).

Os Objetos Educacionais (OE) são softwares interativos, experimentos práticos, vídeos, imagens, sons e mapas. Os OE estão disponíveis no do Banco Internacional de Objetos Educacionais (BIOE), são gratuitos e vinculados as áreas de ensino.

A partir do desenvolvimento do projeto de pesquisa "Implementação de ferramentas de acessibilidade em Objetos Educacionais para a Educação Inclusiva", que visou catalogar, analisar e implementar recursos de acessibilidade em OE disponíveis no BIOE, buscando tornar esses OE inclusivos, surgiram indagações sobre o vinculo da acessibilidade com a inclusão escolar, alguns dos resultados obtidos serão apresentados abaixo.

Os conceitos de acessibilidade e inclusão estão intimamente relacionados. Quando se trata de acessibilidade, o senso comum demonstra que esse conceito está ligado ao uso de espaços físicos.

Segundo Godinho (2010);

A Acessibilidade consiste na facilidade de acesso e de uso de ambientes, produtos e serviços por qualquer pessoa e em diferentes contextos. Envolve o Design Inclusivo, oferta de um leque variado de produtos e serviços que cubram as necessidades de diferentes populações, adaptação, meios alternativos de informação, comunicação, mobilidade e manipulação, produtos e serviços de apoio/acessibilidade.

Sendo assim, a acessibilidade deveria estar em todos os âmbitos, principalmente na perspectiva da educação inclusiva.

O objetivo principal desta pesquisa foi analisar a importância da acessibilidade em OE para o processo de inclusão escolar e aprendizagem dos EPAEE.

\section{METODOLOGIA}

Esta pesquisa Foi realizada mediante o projeto que se encontra cadastrado no Comitê de Ética em Pesquisa (CEP) sobre o protocolo CAAE: 10206912.2.0000.5402,, utilizamos uma abordagem qualitativa.

A pesquisa qualitativa pode ser definida, segundo Minayo (1995, p. 21-22) como:

A pesquisa qualitativa responde a questões muito particulares. Ela se preocupa, nas ciências sócias, com um nível de realidade que não pode ser quantificado, ou seja, ela trabalha com o universo de significados, motivos, aspirações, crenças, valores e atitudes, o que 
corresponde a um espaço mais profundo das relações dos processos e dos fenômenos que não podem ser reduzidos à operacionalização de variáveis.

Tais características torna imprescindível a criação de uma relação indissociável entre o sujeito e o pesquisador. Desse modo, primeiramente, nos inteiramos das deficiências atendidas e seu vinculo no processo de ensino e de aprendizagem visando à inclusão, por meio de pesquisa bibliográfica em literatura especializada.

Os dados foram obtidos a partir de atendimentos pedagógicos semanais, com duração média de uma hora, com dois EPAEE, sendo um com deficiência intelectual (DI) e o outro com Síndrome de Down (SD) no Cpides. A Deficiência Intelectual (DI) tem como base os parâmetros inerentes aos manuais publicados pela antiga AAMR (American Associationon Mental Retardion), atual AAIDD (Associação Americana de Deficiência Intelectual e de Desenvolvimento - em tradução livre). A última edição desse texto, o DSM IV (Manual Diagnóstico e Estatístico de Transtornos Mentais) define a DI como uma deficiência caracterizada por limitações significativas tanto no funcionamento intelectual como no comportamento adaptativo, que abrange as habilidades práticas e sociais, normalmente origina-se antes dos 18 anos de idade.

A Síndrome de Down (SD), por sua vez, ocorre devido a um cromossomo extra presente na célula implicando em uma divisão celular incorreta. Esta formação congênita traz geralmente ao individuo limitações sensoriais, problemas cardíacos, deficiência intelectual, dificuldades motoras, entre outros fatores relacionados ao desenvolvimento motor, social e cognitivo do sujeito.

O comprometimento das funções cognitivas de um indivíduo não o caracteriza como incapaz. Ao menos podemos dizer que essa seria uma informação incompleta, uma vez que as funções cognitivas são funções superiores do sistema nervoso central, que controlam o domínio do raciocínio, da linguagem, de movimentos, etc., e desta forma, o funcionamento incompleto de sua fisiologia acarreta diversidade em graus de comprometimento para o estudante, consequentemente, a maneira de se trabalhar com ele. Contudo, a capacidade de aprender é inerente a todos, mudando somente o tempo e as estratégias de ensino-aprendizagem. (SANTOS, 2012).

Para o processo de análise, foi catalogados $140 \mathrm{OE}$ do BIOE. A partir da seleção e categorização do $\mathrm{OE}$, foram separados e utilizados nos atendimentos ao fim de verificar os recursos de acessibilidade descritos na caracterização do $O E$, e se tais recursos auxiliariam o uso do OE no ensino dos EPAEE.

O quadro de catalogação apresenta o "Título do OE", a "Descrição" que corresponde a um breve resumo sobre o $\mathrm{OE}$, "Itens Ausentes" que se refere aos itens que não se encontram nos OE e caso fosse acrescentados tornariam o OE acessível, "Deficiência" onde são citadas as deficiências que seriam beneficiadas caso fosse um recurso com acessibilidade e o "Link" com o endereço eletrônico para a localização e acesso de cada OE.

Como referencial teórico para os atendimentos utilizamos a Abordagem Construcionista, Contextualizada e Significativa (CCS), que de acordo com Schlünzen (2000, p.28)

Construcionista porque o aluno usa o computador como uma ferramenta para produzir um produto palpável na construção do seu conhecimento e que é de seu interesse. Contextualizado porque o tema do projeto parte do contexto da criança, desenvolvendo-se a partir da vivência dos alunos, relacionando-o com a sua realidade. Significativo por dois motivos: primeiro, no desenvolvimento do 
projeto, os alunos irão se deparando com os conceitos das disciplinas curriculares e o professor mediará a formalização dos conceitos, para que o aluno consiga dar significado ao que está sendo aprendido; segundo, porque cada aluno atuará conforme as suas habilidades e o seu interesse, resolvendo o problema de acordo com aquilo que mais se identifica.

Assim, buscamos auxiliar os estudantes à construção do conhecimento, para que de fato tenha aplicabilidade em sua vida de maneira contextualizada e significativa.

\section{RESULTADOS}

Ao ser realizado a catalogação dos $\mathrm{OE}$, percebemos que, dos 140 objetos analisados, apenas 2 possuía recursos de acessibilidade como áudio descrição e Libras (Língua Brasileira de Sinais). A Áudio descrição é um recurso que consiste na descrição clara e objetiva de todas as informações que compreendemos visualmente e que não estão contidas nos diálogos, como, por exemplo, expressões faciais e corporais que comuniquem algo, informações sobre o ambiente, figurinos, efeitos especiais, mudanças de tempo e espaço, além da leitura de créditos, títulos e qualquer informação escrita na tela. Esse recurso de acessibilidade permite que o usuário receba a informação contida na imagem ao mesmo tempo em que esta aparece, possibilitando que a pessoa desfrute integralmente da obra, seguindo a trama e captando a subjetividade da narrativa. Nesse sentido, este recurso proporcionaria que $O$ OE pudesse ser utilizado por um deficiente visual.

A legenda em língua portuguesa e/ou Libras seriam recursos para acessibilidade de estudantes surdos, uma vez que a legenda é um recurso utilizado também para os estudantes com $\mathrm{DI}$, facilitando assim a compreensão do $\mathrm{OE}$, principalmente quando se tratam dos softwares interativos, imagens, vídeos e áudios.

Assim, para a utilização dos OE nos atendimentos, os que correspondiam aos critérios de acessibilidade, e por isso Utilizamos como base o OE "Fazenda Rived" que tem como objetivo proporcionar o desenvolvimento e a aplicação prática dos conceitos de agrupamento, quantificação, ordenação numérica e contagem. O mesmo vale para o OE "Um dia de compras", com situações adaptadas ao cotidiano. Além dos $\mathrm{OE}$, articulamos ao desenvolvimento das atividades, a utilização de outros recursos que possam auxiliar o desenvolvimento de conceitos de alfabetização, como o uso de jogos pedagógicos como dominó com letras e figuras.

Os resultados diante a utilização dos OE durante os atendimentos se mostram satisfatórios, visto que foi notória a melhora dos dois estudantes em diversos aspectos, sociais em que citamos: a socialização, autonomia e autoconfiança. No aspecto educacional, ao avaliar a aprendizagem dos conceitos da linguagem escrita, evidenciamos que têm compreendido com maior facilidade os fonemas das palavras, o que tem refletido sensivelmente em sua dicção, leitura e escrita. Assim, visualizamos com base nos procedimentos avaliativos, que correspondem a ações delimitadas por Luckesi (2003) de acompanhamento processual, os estudantes têm apresentado melhor desempenho em atividades relacionadas ao desenvolvimento das capacidades cognitivas e também relacionadas ao motor fino, como: facilidade em realizar cálculo mental com operações de soma e subtração com os números naturais e interpretação de situação problema na busca de soluções.

Qualitativamente evidenciamos mudanças positivas nos dois participantes, sendo estas com vistas à melhora em sua qualidade de vida, e no desenvolvimento contínuo no tocante aos aspectos pedagógicos. 


\section{DISCUSSÃO}

Quando se discute sobre educação inclusiva, é importante ressaltar que esta ação não compreende apenas colocar um estudante com deficiência em salas regulares, é um processo que ultrapassa essa perspectiva e que engloba outros fatores como a socialização, autonomia, ensino e aprendizagem.

Mantoan (1998) enfatiza que os processos inclusivos precisam ultrapassar perspectivas de inserção e alcançar propostas que favoreçam o pertencimento, aceitabilidade e a aquisição de conhecimento.

Assim, entendemos que a acessibilidade versa sobre as possibilidades de igualdade, que suprimem barreiras que possibilitem ao outro aprender. Nas ideias de Werneck (2000), acessibilidade possibilita que seja oportunizado equiparação de direitos, para a valorização e reconhecimento da capacidade humana. Assim, é necessário pensar em acessibilidade além das caracterizações arquitetônica para alcançar e romper com outras barreiras que impossibilitem o acesso ao conhecimento, à autonomia e viver em sociedade.

Nesse sentido, observamos neste trabalho dois pontos divergentes; o primeiro evidencia a potencialidade para o ensino e para aprendizagem da utilização dos $\mathrm{OE}$, como recursos efetivos para os estudantes com deficiência e que favorecem a inclusão; o segundo trata que a maior parte dos OE não possuem recursos que compreendam acessibilidade, e que limitam o manuseio por parte dos EPAEE, dificultando processo autônomos e totalmente inclusivos.

Acreditamos que, ao se pensar em recursos que possibilitem o acesso, usabilidade, manuseio, ensino, autonomia, reflexão, e aprendizagem, de todos, não compreende e distancia de propostas adaptativas. Acreditamos que a acessibilidade vem ao encontro de ideias que valorizam as potencialidades humanas e que evidenciam na diferença, maneiras diferentes de pensar, pois "somos diferentes, mas não queremos ser transformados em desiguais. As nossas vidas só precisam ser acrescidas de recursos especiais ${ }^{1 "}$.

\section{CONCLUSÃO}

Partindo do pressuposto de que todos nós temos direito a um ensino de qualidade, entre outras necessidades, consideramos que a utilização dos OE apresenta-se como possibilidade relevante ao processo de inclusão, de ensino e aprendizagem do EPAEE, pois seu uso possibilita a contextualização das atividades, auxiliando no processo de construção e significado dos conceitos aprendidos, além de favorecer sua autonomia.

Por outro lado percebemos que a falta de recursos de acessibilidade nos OE dificultam processo inclusivos, que pressupõem ações autônomas de aprendizagem, e também de ensino. Segundo Mantoan (1998, p.06)

A educação inclusiva implica a criação de alternativas metodológicas que contenham, em seus princípios e na sua operacionalização, meios de se proporcionar experiências de escolarização que se adaptem às exigências curriculares, às características e às especificidades do processo educativo dos aprendizes, diminuindo ou eliminando os obstáculos do meio escolar que produzem as inadaptações escolares dos alunos em geral, deficientes e não deficientes.

Portanto, acreditamos que a acessibilidade pedagógica versa sobre a possibilidade de inclusão plena, e por isso se apresenta como uma necessidade educativa emergente.

\footnotetext{
${ }^{1}$ Trecho da Peça de teatro: Vozes da Consciência, BH. 2009 


\section{REFERÊNCIAS}

Associação Americana sobre Deficiência Intelectual e Desenvolvimento (AAIDD). Disponível em: < http://aaidd.org/home>.

BIOE- Branco Internacional de Objetos Educacionais. Disponível em: < http://www.objetoseducacionais2.mec.gov.br/>.

BRASIL: Ministério da Educação. Secretaria de Educação Especial. Política Nacional de Educação Especial na perspectiva da Educação Inclusiva. Brasília: MEC/SEESP, 2008.

GODINHO, Francisco. Conceito de Acessibilidade. Disponível em: http://creago.org.br/site/acessibilidade/. Acesso em: 26 de junho 2016.

MANTOAN, Maria Teresa Eglér. Educação escolar de deficientes mentais: Problemas para a pesquisa e o desenvolvimento. Cad. CEDES, vol. 19, n.46, Campinas, set. 1998.

MINAYO, Maria Cecília de Souza. O Desafio do Conhecimento: pesquisa qualitativa em saúde. São Paulo, Rio de Janeiro: HUCITEC/ABRASCO, 1995.

SANTOS, DaísyCléia Oliveira dos. Potenciais dificuldades e facilidades na educação de alunos com deficiência intelectual. Educ. Pesqui., São Paulo, v.38, n. 04, p. 935-948, out./ dez. 2012.

SCHLÜNZEN, E. T. M. Mudanças nas práticas pedagógicas do professor: Criando um Ambiente Construcionista, Contextualizado e Significativo para Crianças com Necessidades Especiais Físicas. 2000. 212 f. Tese (Doutorado em Educação), Pontifícia Universidade Católica de São Paulo, São Paulo, 2000.

WERNECK, Claudia. Ninguém mais vai ser bonzinho, na sociedade inclusiva. Rio de Janeiro: WVA Editora, 2000. 